\title{
Field test on thermal response characteristics of an energy pile in underground row piles
}

\author{
Gangqiang Kong ${ }^{1}$, Yang Zhou ${ }^{1 *}$, Di $\mathrm{Wu}^{2}$, Gaoxiang Yin ${ }^{3}$ and Hefu $\mathrm{Pu}^{4}$ \\ ${ }^{1}$ College of Civil and Transportation Engineering, Hohai University, Nanjing, China; \\ ${ }^{2}$ Qingdao University of Technology, Qingdao, China; \\ ${ }^{3}$ China Design group Lo.,LTD, Nanjing, China; \\ ${ }^{4}$ Huazhong University of Science and Technology, Wuhan, China.
}

\begin{abstract}
Underground row piles are usually used in excavation of underground structures and abandoned after structural construction. The heat exchanger tubes embedded in the underground row piles can be severed as energy piles, which can exchange shallow geothermal energy. The construction process of the energy pile in the underground row piles was introduced. Compared with the traditional single energy pile, there is a special characteristic of the energy pile in underground row piles: piles are linked as a whole by the top beam at the top of the row pile. Field tests on the thermal response and thermo-mechanical characteristics of the energy pile in underground row piles were performed. The stable input power of 2.07 $\mathrm{kW}$. The distribution of temperature, strain, and stress of pile body along depth were measured and discussed. It shows that the measured comprehensive thermal conductivity coefficient of soil is $3.72 \mathrm{~W} /(\mathrm{m} \times \mathrm{K})$. In the thermo-mechanical analysis after heating, due to the end restrains by the top beam and toe in stiff rock, the rate of thermal stress to temperature change at the top and toe are $-0.101 \mathrm{MPa} /{ }^{\circ} \mathrm{C}(34 \%$ of fully restrain) and $-0.061 \mathrm{MPa} /{ }^{\circ} \mathrm{C}(20 \%$ of fully restrain).
\end{abstract}

\section{Introduction}

With the rapid development of economies, it is faced with the phenomenon of ground space congestion. Urban designers have turned their attention to the underground space and built tunnels and comprehensive pipe galleries under the ground. In the construction process of these infrastructures, the underground support piles are widely used to minimize the excavation induced impact $[1,2]$. However, after the completion of the underground infrastructure construction, the pile rows for underground support are often buried in the ground and abandoned, which causes a great waste. In order to maximize the utilization of resources, the heat exchange pipe embedded in the pile foundation of the underground support row piles is used to form the energy pile, so that the surrounding buildings and the underground soil can exchange the shallow ground temperature energy through the energy pile in the underground support row piles after the underground infrastructure construction.

Several full-scale experiment evaluation has been performed to investigate the effect of thermo-mechanical load on the pile behaviors [3-8] under thermal load only or thermo-mechanical load. Laloui et al. [4] tested an energy pile by undertaken different stages of construction so that the pile head restrain can be quantified. Bourne-Webb et al. [6] tested an isolated pile loaded at Lambeth College (London). The thermal load (heating and cooling) and constant mechanical load was imposed to the pile. By testing the heat exchange performance of the energy pile under thermal load only, Gao et al. [7] analyzed the thermal conductivity and thermal resistance and additional stress and strain.

The top beam makes the single energy pile the other piles in the underground support row unite into a whole. When the energy pile is running, it is affected by the resistant by the top beam. In order to understand the thermal response characteristics of energy piles in the underground support piles, the tests were carried out.

\section{Specifications of project}

\subsection{Engineering background}

In this paper, the test is based on the project of excavation for the electric power pipelines, which is located in Nanjing, China. A utility tunnel is used to install the electric power pipelines. The utility tunnel is mainly divided into one main channel and three branch channels. One of the branch channel was selected as testing section. According to the soil properties, the soil can be divided into four engineering geological layers: miscellaneous fill, silty clay1, silty clay 2 , andesite 1 and andesite2. Figure 1 plots the in-situ geological profiles, physical and mechanical properties including natural water content, plastic limit and liquid limit, density, constrained modulus. The supporting piles in double

\footnotetext{
* Corresponding author: zhou1991yang1010@163.com
} 
rows are used to retain lateral earth pressure and antiseepage in pit excavation for the utility tunnel. Top beams are set on the top of a row pile to unite row piles. The two beams on the top of piles are also connected by horizontal beams. The pile type is bored cast-in-place pile with diameter of $0.8 \mathrm{~m}$ and length of $15.0 \mathrm{~m}$. The spacing between pile centers in every row is $1.1 \mathrm{~m}$. One of these bored piles is selected as energy pile for heat response investigation.

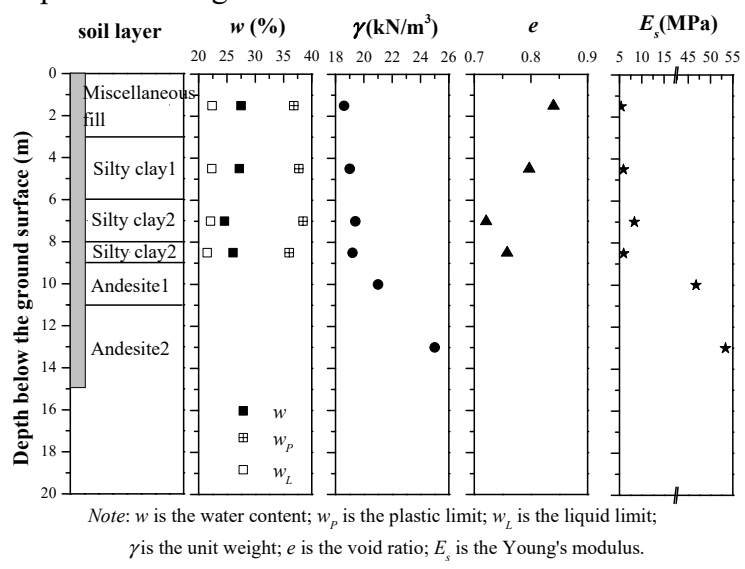

Fig. 1. Physical and mechanical properties of soils in site.

\subsection{Field construction of energy pile}

As shown in Fig. 2, the construction flows of the energy pile contains three steps: binding of reinforcement cages and instruments, pour concrete for the pile, and conduct the top beam.

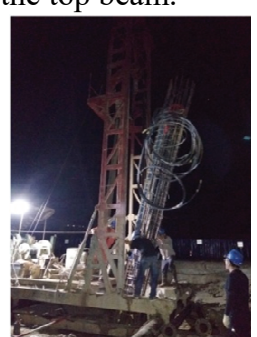

(a)

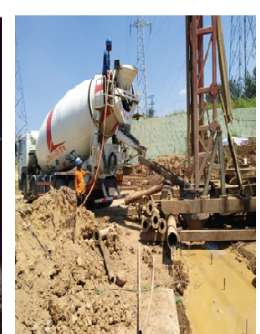

(b)

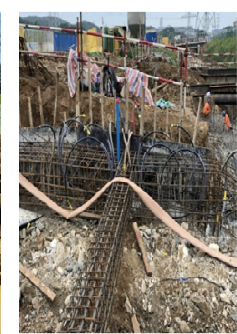

(c)
Fig. 2. In-situ photos of construction processes of energy pile: a) Install the cage with tubes and sensors; b) Cast concrete; c) Conduct top beam construction.

After the reinforcement cage is made, the heat exchange pipe, vibrating-wire strain gauges (VWSG), and thermometer are bound on the reinforcement cage to fix their positions and prevent movement.

PE25 pipe is used as the heat exchange pipe in the energy pile. $3 \mathrm{U}$ pipe in series is used as the heat loop. Nylon ties and iron wires are used to evenly arrange the heat exchange tube on the longitudinal reinforcement of the reinforcement cage. The distance between the bottom of the heat exchange tube and the bottom of the pile is $1.5 \mathrm{~m}$. The upper elbow of the $3 \mathrm{U}$ heat exchange tube is $1.5 \mathrm{~m}$ below the top of the pile. The total length of the energy pile heat exchange tube is $88.0 \mathrm{~m}$. The binding form of the heat exchange tube is shown in Figure 3.

The VWSG is used as the stress sensor in the pile, which can measure the stress of the pile body. The temperature on the pile body is monitored by thermometer. Two groups of 10 sensors symmetrically at the places at $1.5 \mathrm{~m}, 4.0 \mathrm{~m}, 6.5 \mathrm{~m}, 10.0 \mathrm{~m}$ and $13.5 \mathrm{~m}$ away from the pile top of the pile respectively.

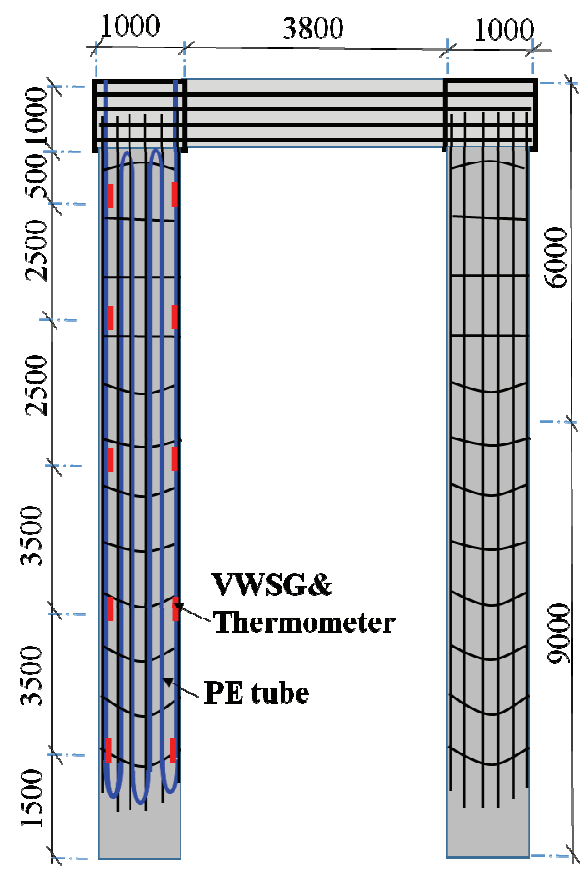

(a)

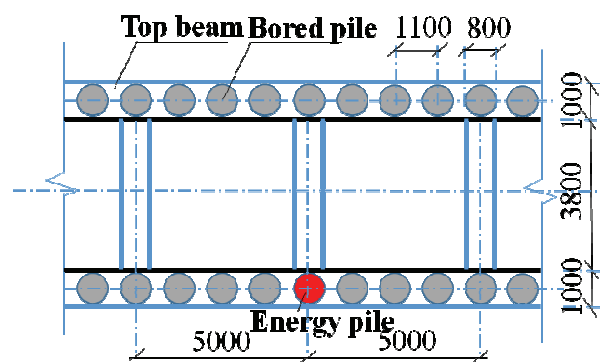

(b)

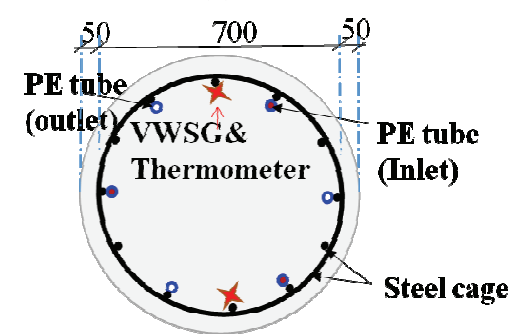

Unit: $\mathrm{mm}$

(c)

Fig. 3. Schematic diagram of energy pile in the row of piles and the layout of tubes and sensors; a) layout of piles; b) cross section of the construction; c) layout of instruments.

After the completion of installing the reinforcement cage and sensors, the pouring work of the cast-in-place pile is carried out. C30 concrete is used for pouring, and the hydration heat is produced during the pouring process. After the strength of pile body concrete is formed, the pile head breaking process shall be carried out. In this process, the pipe or wire of the heat exchange tube and instruments in the energy pile shall be protected, 
and extended from the top of the top beam in the subsequent top beam construction.

\subsection{In-situ testing system and processes}

In-situ experiments on thermal and thermo-mechanical performance of the energy pile were carried out in the project in Nanjing, China. The view of the experimental system is shown in Fig. 4. The experimental system consists of the energy pile, constant temperature water tank, flow meter, flow rate adjust valve, temperature sensors and digital thermo meters. Heat was applied to the circulating water in the constant temperature water tank with heaters and released to the soil through the energy pile.

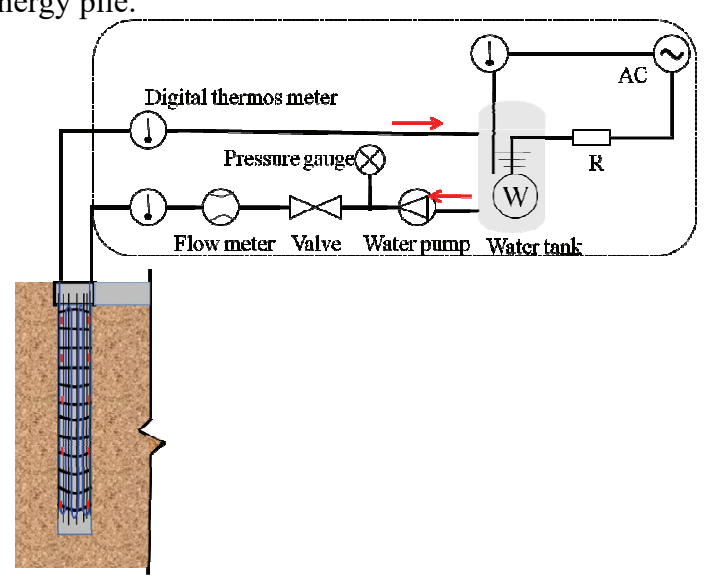

Fig. 4. Experimental system for the thermal response test of energy pile.

The inlet water temperature was set in the constant temperature water tank by adjusting the heaters. The detailed information in this test is present as follows:

- The temperatures of inlet and outlet water were measured by digital thermos meter with a precision of $0.15{ }^{\circ} \mathrm{C}$.

- Volumetric flow rate was measured by a turbine flow meter with a precision of $0.005 \mathrm{~m}^{3} / \mathrm{h}$.

In order to fully estimate the thermal and thermomechanical performance of the in-situ energy pile, thermal response test (TRT) was adopted in this investigation. The TRTs in this study were conducted with the constant input power of $3 \mathrm{~kW}$ to simulate the operating condition of energy pile in summer. The $3 \mathrm{U}-$ shaped loops are investigated. The thermo-mechanical behaviors of the energy pile under thermal load only were investigated.

\section{Results and analysis}

\subsection{Hydration heat in the energy pile}

A large mass of concrete was pouring into the energy pile at the data (July 20,2018). Due to the hydration heat dissipation of concrete, the temperatures of pile body decreased, which were monitored by the thermometers at different depths. The hydration heat of concrete can be divided into three stages [9]: hydration heat concentration $(\leqslant 3 \mathrm{~d})$, hydration heat dissipation (3-30d) and ground temperature stabilization $(\geqslant 30 \mathrm{~d})$. Due to disturb of in-situ construction, the process of pile body temperature rising at first stage was not recorded. At the later steps, the temperature gradually then recovers to the initial soil temperature line as the concrete hydration heat is dissipated. After stabilization, the TRTs were carried out on the energy pile, which were not affected by the hydration heat of concrete.

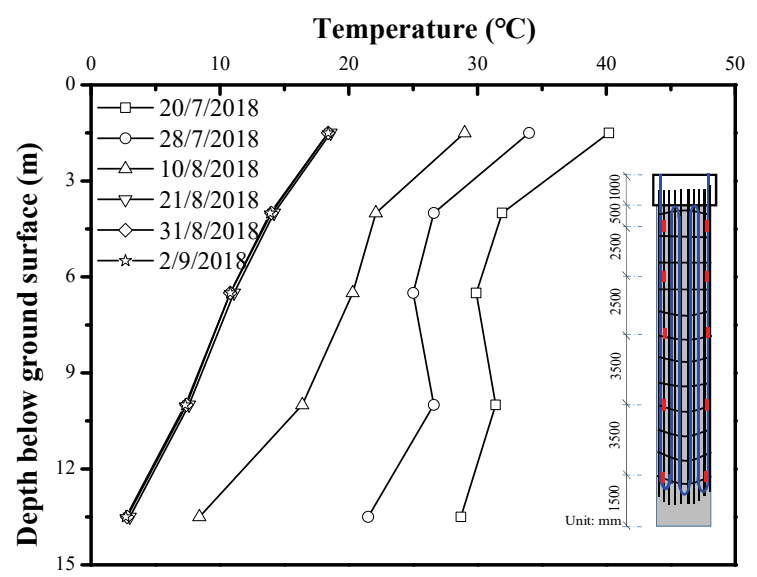

Fig. 5. Heat dissipation of concrete hydration along pile depth with time delaying.

\subsection{Thermal response}

During the test, the ambient temperature and the water temperature at the inlet / outlet of the energy pile are shown in Figure 6. The test time is from September 2, 2018 to September 25, 2018 (307h in total). During the test, the average ambient temperature is about $30.0{ }^{\circ} \mathrm{C}$; after heating for $307 \mathrm{~h}$, the inlet water temperature reaches $48.5{ }^{\circ} \mathrm{C}$, and the outlet water temperature changes from the initial $27.1{ }^{\circ} \mathrm{C}$ to $46.2{ }^{\circ} \mathrm{C}$. With the increase of operation time, the water temperature at the inlet and outlet showed an increasing trend. After 113h, the water temperature at the inlet and outlet tended to increase smoothly. Due to the complex site conditions, the large temperature difference between day and night in summer and the limitations of heat exchange tube insulation, there is a slight fluctuation in the inlet / outlet water temperature.

In summer, the underground temperature is far lower than the temperature of the heat transfer liquid in the heat exchange tube. With the circulation of the heat transfer liquid, the heat is transferred from the pile to soil body, resulting in the outlet water temperature lower than the inlet water temperature. The difference between the inlet water temperature and the outlet water temperature is the energy lost by the heat transfer liquid, and also represents the heat transferred to the pile and soil body, so according to the power can be obtained by the water temperature difference, the mass and flow rate of the conduction liquid:

$$
Q=v \rho_{\text {fluid }} c_{\text {fluid }}\left(T_{\text {in }}-T_{\text {out }}\right)
$$

Where: $v$ is the flow rate of liquid $\left(\mathrm{m}^{3} / \mathrm{s}\right), \rho_{\text {fluid }}$ is the density of heat-conducting liquid $\left(\mathrm{kg} / \mathrm{m}^{3}\right), c_{\text {fluid }}$ is the 
specific heat capacity of heat-conducting liquid $(\mathrm{J} /(\mathrm{kg} \times$ $\mathrm{K})$ ), $T_{\text {in }}$ and $T_{\text {out }}$ is the inlet water temperature $\left({ }^{\circ} \mathrm{C}\right)$, and the outlet water temperature $\left({ }^{\circ} \mathrm{C}\right)$, respectively.

When analyzing the thermal response test results, the linear heat source model is widely used to study the theoretical model of the ground source heat pump. The conditions of the model: at a constant heating power $Q$ and a constant flow velocity $v$ is:

$$
\begin{gathered}
T_{f}(t)-T_{g}=\frac{q}{4 \pi \lambda} \operatorname{In}(t)+q\left\{R_{b}+\frac{1}{4 \pi \lambda}\left[\operatorname{In}\left(\frac{4 \alpha_{\mathrm{s}}}{r_{b}^{2}}\right)-\gamma\right]\right\} \\
T_{f}(t)=\frac{T_{\text {in }}(t)+T_{\text {out }}(t)}{2}
\end{gathered}
$$

in which $q=Q / L$ is the heat exchange rate per unit length of the effective length, $L$ is the effective length of the heat exchange body, $t_{\mathrm{g}}$ is the temperature at the steady state of the soil body, $R_{\mathrm{b}}$ is the thermal resistance of the energy pile, $r_{\mathrm{b}}$ is the radius of the heat exchange body, $\alpha_{\mathrm{s}}$ is the heat diffusion rate of the soil body, and $\gamma$ is the Euler constant.

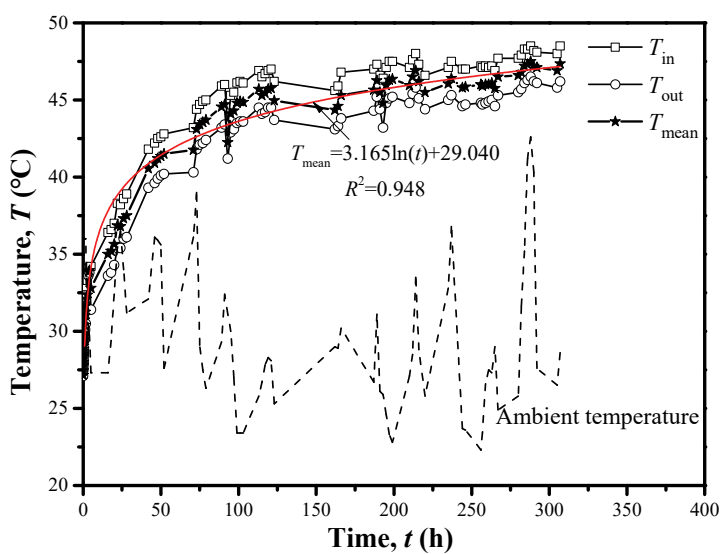

Fig. 6. Inlet/outlet water temperature over time before soil excavation.

When $q$ is constant, the fluid temperature $T_{f}(t)$ is linear with $\ln (t)$, and its slope is $k$. The expression is shown in following:

$$
T_{f}(t)=k \operatorname{In}(t)+b
$$

From the above, the comprehensive thermal conductivity coefficient of soil mass:

$$
\lambda=q / 4 \pi k
$$

According to the field test, the heat conducting liquid is water with a flow rate of $0.71 \mathrm{~m}^{3} / \mathrm{h}$, a density of $1000 \mathrm{~kg} / \mathrm{m}^{3}$ and a specific heat capacity of $4200 \mathrm{~J} /(\mathrm{kg} \times$ $\mathrm{K})$, there is fluctuation in the temperature difference between the inlet and outlet at the early stage of the test, and the test data at the later stage of the test is relatively stable. The average water temperature difference between the inlet and outlet is about $2.5^{\circ} \mathrm{C}$. Therefore, according to formula (1), the actual power is $2.07 \mathrm{kw}$. The effective length of the energy pile is $14.0 \mathrm{~m}$. The heat exchange rate of the unit effective length can be obtained is $148 \mathrm{w} / \mathrm{m}$.

According to formula 3 and formula 4 , the slope of fluid temperature and $\ln (t)$ is 3.165 . The comprehensive thermal conductivity coefficient of soil obtained in this field test is $3.72 \mathrm{~W} /(\mathrm{m} \cdot \mathrm{K})$.

\subsection{Thermo-mechanical performance}

The sign convention adopted is

1) temperature increment due to heating: positive

2) thermal expansive strain due to heating in the pile: positive

3) tensile strain in the pile: positive

4) tensile axial load or stress in the pile: positive

5) upwards friction: positive.

Before the test, the temperature at the top of the pile is much higher than that at the bottom of the pile due to the influence of the external environment temperature. The temperature tends to decrease with the increase of the depth. With the operation of the test, the temperature at each point of the pile body increases significantly. In summer, the pile top is close to the ground, which is more affected by the environment temperature. The position of $1.5 \mathrm{~m}$ deep increased about $12.0{ }^{\circ} \mathrm{C}$. The average temperature change of the pile is about $20.5^{\circ} \mathrm{C}$. Meanwhile, the strain changes in the pile body were recorded by the VWSGs. Figs. 7 (a) shows the actual temperature changes and the axial strain profiles along the pile after heating.
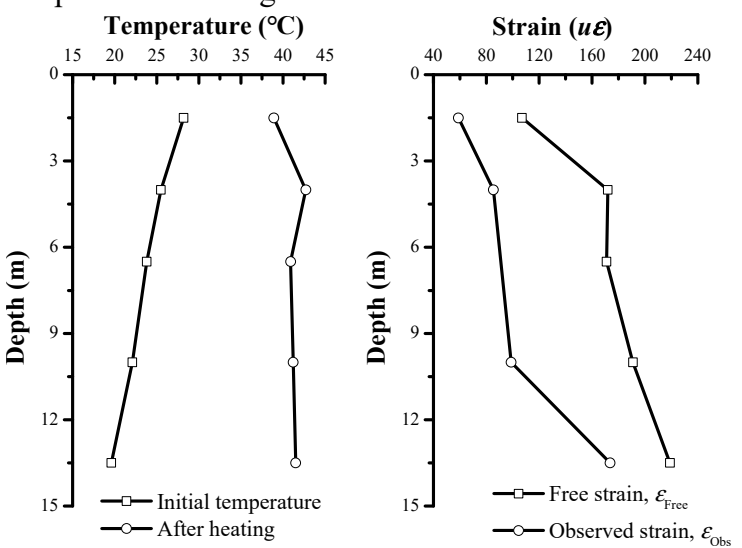

Fig. 7. Temperature and strain distribution along the depth after heating.

In the process of heating the pile by heat-transfer fluid, the pile will expand with the increase of temperature. The axial direction of the pile is constrained by the side friction and the end of the pile, so that the actual axial deformation of the pile is less than the free expansion deformation of the pile. The difference between the free expansion deformation and the actual deformation is the strain produced by the restraint stress. Therefore, the pile is subject to thermal expansion and the axial restraint force is the pressure. The calculation formula is as follows:

$$
\sigma_{\mathrm{a}}=E\left(\varepsilon_{\text {Free }}-\varepsilon_{\text {Obs }}\right)
$$

where $E$ is the elastic modulus of concrete, and the concrete strength of pile and crown beam is $\mathrm{C} 30$. $\varepsilon_{\text {Free }}$ is the strain produced by the free expansion of pile body under unrestricted heating, and $\varepsilon_{0 b s}$ is the actual strain produced by the pile body.

The calculation formula of the strain caused by the free expansion of the pile is:

$$
\varepsilon_{\text {Free }}=\alpha \cdot \Delta T
$$


where $\alpha$ is the thermal expansion coefficient of concrete and the coefficient is $10 u \mathcal{E} /{ }^{\circ} \mathrm{C}, \triangle T$ is the temperature difference between the test and the initial state.

The calculation formula of the skin friction is given as follows:

$$
\tau=\frac{\left(\sigma_{\mathrm{j}+1}-\sigma_{\mathrm{j}}\right) D}{4 \Delta l}
$$

where $D$ is the pile diameter, $j$ is the location of the axial VWSGs and $\Delta l$ is the distance between the axial VWSGs.

The observed strain is quite littler than the free strain at the pile end, which is consistent with the analysis on the effect of thermal load on pile with end restraint imposed (Bourne-Webb et al. [6]). The thermal stress is largest at mid-depth. Due to the end restraint at the bottom and the top beam on the top, the thermal stress at the two ends is not zero. The thermal stress and friction distribution along the pile is shown in Fig. 8.

In response to heating and pile movements, negative shaft friction developed over the upper part of the pile and positive over the lower, as shown in Fig. 8. The shaft friction at upper and lower parts is about 95 and $85 \mathrm{kPa}$. As shown in Fig. 9, the variation of thermal stress with temperature change is present. An approximately linear increase in axial stress with temperature is observed. The completely constrained condition shows that when the side frictional force around the pile is strong enough, it can completely restrain the thermal strain caused by temperature change $\left(-0.3 \mathrm{MPa} /{ }^{\circ} \mathrm{C}\right)$.

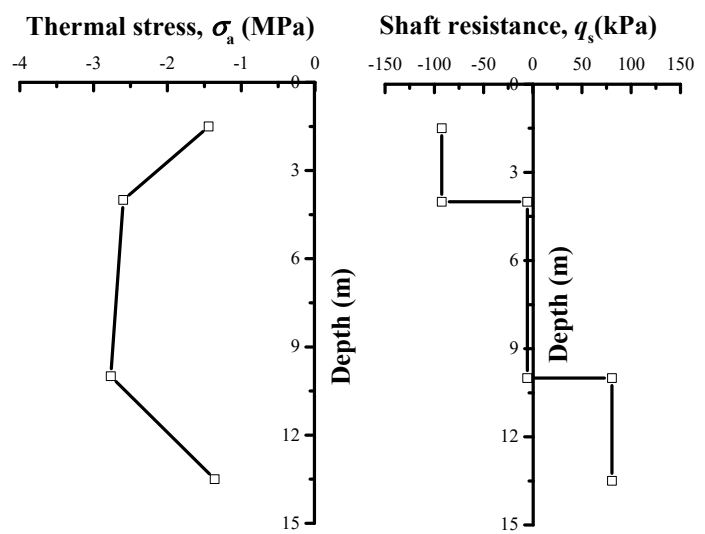

Fig. 8. Thermal stress and friction along the depth after heating.

The observed maximum rate was $-0.136 \mathrm{MPa} /{ }^{\circ} \mathrm{C}$ ( $45 \%$ of maximum) at heating thermal load, respectively. Clearly, due to the end restrains by the top beam and toe in stiff rock, the pile is partial restrained against thermal induced deformation. After heating under thermal load only, the rate at the top and toe are $-0.101 \mathrm{MPa} /{ }^{\circ} \mathrm{C}(34 \%$ of maximum) and $-0.061 \mathrm{MPa} /{ }^{\circ} \mathrm{C}(20 \%)$.

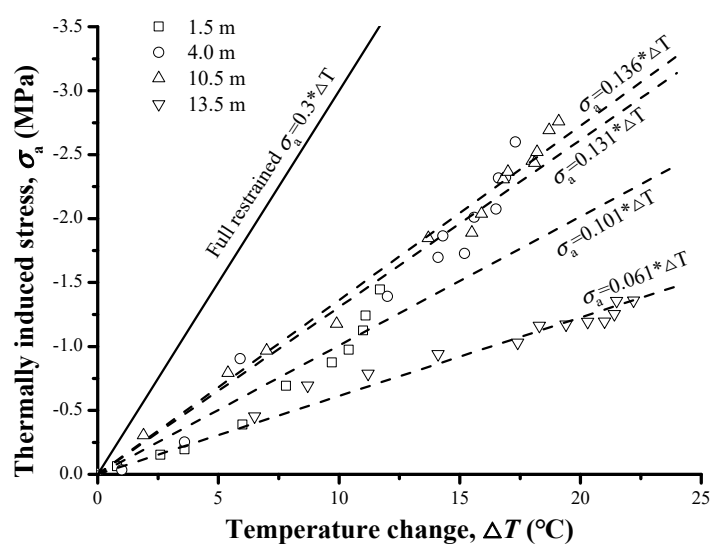

Fig. 9. Thermal stress and friction along the depth after heating.

\section{Conclusions}

This investigation introduces the construction process of the energy pile in the pile row of the underground support, so that the pile can still provide function after being buried without being abandoned. Based on the field test of the energy pile, the thermal response and thermo-mechanical behaviors of the energy pile in the underground support row pile were investigated. The following conclusions are obtained:

1) With the increase of the operation time, the heat exchange rate of the unit effective length can be obtained is $148 \mathrm{w} / \mathrm{m}$, and the comprehensive thermal conductivity coefficient of the soil is $3.72 \mathrm{~W} /(\mathrm{m} \cdot \mathrm{K})$;

2) In the thermo-mechanical analysis, due to the end restrains by the top beam and toe in stiff rock, the pile is partial restrained against thermal induced deformation. After heating under thermal load only, the rate of thermal stress to temperature change at the top and toe are $-0.101 \mathrm{MPa} /{ }^{\circ} \mathrm{C}(34 \%$ of fully restrain) and -0.061 $\mathrm{MPa} /{ }^{\circ} \mathrm{C}(20 \%$ of fully restrain).

The research was financially supported by the National Science Foundation of China (No. 51778212).

\section{References}

1. Z.J. Zhang, M.G. Li, J.J. Chen, J.H. Wang, F.Y. Zeng. Innovative construction method for oversized excavations with bipartition walls. J. Constr. Eng. Manage 143, 8 (2017) 04017056.

2. O. Demeijer, J.J. Chen, M.G. Li, J.H. Wang, C.J. $\mathrm{Xu}$. Influence of passively loaded piles on excavation-induced diaphragm wall displacements and ground settlements. Int. J. Geomech. 18, 6 (2018) 04018052.

3 . H. Brandl. Energy foundations and other thermoactive ground structures. Géotechnique, 56, 2 (2006) 81-122.

4. L. Laloui, M. Nuth, L. Vulliet, Experimental and numerical investigations of the behaviour of a heat exchanger pile, Int. J. Numer. Anal. Meth. Geomech. 30 (2006) 763-781. 
5. D. Wang, L. Lu, P. Cui, Simulation of thermomechanical performance of pile geothermal heat exchanger (PGHE) considering temperature-depend interface behavior. Appl. Therm. Eng. 139 (2008) 356-366.

6. P. Bourne-Webb, B. Amatya, K. Soga, T. Amis, C. Davidson, P. Payne, Energy pile test at Lambeth College, London: geotechnical and thermodynamic aspects of pile response to heat cycles, Géotechnique 59 (2009) 237-248.

7. J. Gao, X. Zhang, J. Liu, K. S. Li, J. Yang. Thermal performance and ground temperature of vertical pile-foundation heat exchangers: A case study. Appl. Therm. Eng. 28(17-18) (2008) 2295-2304.

8. K.D. Murphy, J.S. McCartney, K.S. Henry. Evaluation of thermo-mechanical and thermal behavior of full-scale energy foundations. Acta. Geotech, 10,2 (2015) 179-195.

9. S. You, X. H. Cheng, H. Guo, Z.Q. Yao. In-situ experimental study of heat exchange capacity of CFG pile geothermal exchangers, Energy and Buildings 79 (2014) 23-31. 